aged thirty-five, was admitted into Lydia ward on June 2 nd, 1880. She was a married woman, and mother of three children. Ten years before admission she had typhoid fever, and after this she was troubled with her water. It was scanty, and caused pain when passing. Seven years before admission she passed a large stone, and since, on and off, she had suffered with urinary trouble and incontinence. She had passed gravel at times.

On admission she complained of pain down the back and in the loin. Her general health was not bad. Urine was acid and blood-stained, and was constantly dribbling.

On June 4th she was put under chloroform and the bladder was examined, and a copious phosphatic deposit was found. Next day the bladder was washed out with warm water. A week later she was able to retain urine for a quarter of an hour. From this time she continued to improve, and on July 16th she left the hospital, well able to retain her urine for two hours, and to pass it without pain. On June 28th the temperature rose to $103^{\circ}$, but fell next day to $100^{\circ}$. Un July 2 nd it was normal, and did not afterwards rise above this level.

Piece of Catheter Broken in Bladder : Formation of Stone; Cystotomy ; Old Perineal Section; Well. (From notes by Mr. Pitt.) - Thos. II-, aged forty, was admitted into Job ward on June 19th, 1879. He was married, and his wife had had one child. He had had gonorrhoea twice, last time sixteen years ago, and had always since had difficulty in passing water. In December, 1874, he was ad. mitted under Mr. Bryant, and Syme's operation was performed for stricture and extravasation of urine. He remained in hospital until September, 1875, and was then discharged convalescent, but passing his urine through the perineum, the penile portion of the urethra being quite obliterated. Since then he had always passed a catheter regularly about every third week. Four months before readmission, when using a No. 4 catheter part broke off, and remained in the bladder. $A$ No. 8 was passed frequently afterwards. About a month later he began to feel a burning sensation at the neck of the bladder ; his water became dark, and deposited a thick light-coloured sediment.

On admission he seemed in moderate health. Pulse and temperature normal. When standing he passed water by the perineal opening. There was no blood or albumen in the urine. The meatus urinarius was quite closed, and had been so since he was in the hospital four years before. On June 24th he was put under chloroform, and lateral cystotomy was performed, the staff being introduced through the perineum. A piece of catheter, thickly coated with phosphates, was removed, measuring about tirree-quarters of an inch by one-third of an inch.

Everything went on well, and on July 8th the patient was discharged. The incision was nearly granulated up, and the patient was able to retain his water as usual. Tem. perature never rose above normal.

\section{ROYAL INFIRMARY, GLASGOW.}

\section{CASE OF LEAD POISONING, ENDING IN CONVULSIONS AND DFATH.}

(Under the care of Dr. Charteris.)

For the following notes we are indebted to Mr. J. Macpherson Lawrie, resident physician.

William W-aged sixteen, worker in a pottery, was admitted on the 22nd September last, complaining of paralyzis of both wrists, of six weeks' duration. The family history was unimportant. The boy had been employed in a pottery in Glasgow for the last five years.

At a certain stage of the manufacture of earthenware, the various products are rubbed against each other in order to smooth away any roughnesses and irregularities. In this way a fine dust is disseminated, containing a small percentage of lead. At a later period they are dipped into a thick glazing solution containing 10 per cent. of white lead, and afterwards placed on a convenient perforated shelf to drain. The boy's duty was to lift the articles from the shelf on to another receptacle, for removal to the furnace. Most probably the poison had been introduced into the system through eating food with dirty hands.
The patient was in fairly good health till six weeks before admission, when his attention was attracted to a slight weakness in both wrists, which he thought due to over fatigue, and paid no attention to. This symptom gradually became more marked, and in the course of a week he was unable to raise his hands in the slightest degree. He remained at his work, and fell off in general health. About a month after the commencement of his ailment he suffered from cramps, occurring chiefly at night, in front of both thighs. These were followed by severe pain in his abdomen, accompanied by constipation. Under the influence of remedies the abdominal symptoms ontirely disappeared in four days, and his bowels returned to their normal condition.

On examination the patient was found rather emaciated, with a heavy exhausted appearance, and in a very unsatisfactory state of health. When his arms were raised, the hands hung down in a helpless manner, like the forepaws of a kangaroo. The muscles of both arms were wasted and soft. The action of the supinator longus, when the forearm was extended against the patient's will, was found as usual intact. An interrupted electrical current applied over the extensor muscles was followed by no response. On the flexor aspect slight contractions of the fingers were produced. His gums exhibited the characteristic blue line. His teeth were coated with tartar, and somewhat discoloured. The abdomen was quite natural in appearance, soft, and elastic, and pressure caused no pain. His pupils were dilated. The sight was quite natural. The pulse was rather weak and about 70 per minute. His urine was found to have a specific gravity of 1012, neutral, of pale colour, without sediment, and without albumen; phosphates appeared on heating, but otherwise the physical examination yielded normal results.

The patient was put on six grains of iodide of potassium three times a day, and nourishing food, with maltine. Three days afterwards he complained of very severe cramps in the knees. They were relieved for a time with equal parts of belladonna, opium, and chloroform liniments, applied on lint, with a poultice over all. Subsequently the cramps returned, and proved extremely obstinate under treatment. The iodide of potassium was reduced to threegrain doses, and subsequently replaced by the bromide in two-grain doses every four hours without any relief to the symptoms. On the 30 th, about 7 A.M. (eight days after admission) the nurse on night duty reported that the patien was getting into a "stupid condition." $\mathrm{He}$ was visited at once and found in a semi-comatose state, replying to ques. tions in a vague manner when roused up. In the course of ten minutes he suddenly uttered •a loud cry and was attacked with severe clonic convulsions, first on one side of his body (the right), then on the other, involving the head as well as the limbs, and latterly extending to the trunk. These symptoms were accompanied by complete unconsciousness, insensible and dilated pupils, foaming at the muuth, retracted abdomen, involuntary micturition, with a pale, clammy face and rapid and forcible action of the heart. In a few minutes the convulsions ceased, but he still remained comatose. Within the course of two or three hours he had nine or ten repetitions of the attack. During the remainder of the day he lay in a restless state with dilated pupils, but could not be got to answer any questions. His parents stated that they had never observed such symptoms before in the boy. Next morning his condition was the same. His bowels were cleared out with sulphate of magnesia assisted by an enema of soap and water. Chloral hydrate was administered in one and a quarter grain doses every hour, the bromide of potash being discontinued. In the evening his pulse became very rapid, breathing rather stertorous, and temperature $102^{\circ}$. On Oct. 2nd his urine was again examined and found to contain a good deal of albumen, but no lead was detected either with sulphuric acid or iodide of potassium. On Oet. 3rd he was evidently sinking. Towards night his breathing became very shallow and hurried-over sixty respirations per minute. His pulse was weak and thready and about 130. He sank yery gradually, and death took place at 11.50 P.м.

Remarks. - In this case the epileptic symptoms commenced eight days after admission, and remained till he expired, nearly four days afterwards. During this period he had only one or two snatches of sleep for about half an hour at a time. As far as could be ascertained he was only con. scious on one occasion, when the recognised and named his mother and brother. He took nourishment well all through, 
averaging about two pints of milk and beef-tea each in the twenty-four hours. The attacks of convulsions occurred at intervals of about two hours, diminished to one hour towards the end, and were all marked by the same characters as those first noticed.

A partial post-mortem examination was made, permission being only granted to examine the head, and to a limited extent the abdomen. The brain presented to the naked eye nothing abnormal. The organs of the abdomen were also apparently healthy. Portions of muscle from the left forearm were excised, and after being hardened in alcohol and solution of chromic acid, fine sections were made; these sections were stained with logwood, and subjected to micro. scopic examination. For the sake of comparison, the supinator longus was taken as normal, and with it was compared the extensor carpi radialis longior. In the latter, which was one of the muscles paralysed, there were observed, even in untinted specimens, parts in which the muscular fibres were markedly narrower than normal. This condition was not present everywhere, but, on the contrary, there were places where the cylinders were of normal diameter, this being confirmed by their measurements being the same as that of the fibres in the supinator longus. From a series of measurements the narrowed fibres were found to be on the average about half the diameter of the normal ones. The narrowed fibres existed in groups, although there were occasional single fibres of a narrow diameter. The transverse stria in both sets of fibres were found to be equally distant, indicating that the narrowing was not due to a different state of contraction. It was also observed that in the narrowed fibres the transverse striæ were very much less marked than in the normal, being sometimes almost, or entirely, lost. These conditions were easily made out in unstained specimens, but the condition of the muscular nuclei was best determined in specimens treated with logwood. In the paralysed muscle it was at once seen that the nuclei were more abundant than in the normal, and this was, to a slight extent, the case even in fibres of nearly normal diameter. But when the narrow fibres were examined an enormous increase of the nuclei was observed, these being closely set, and in some cases almost concealing the fibres. It is impossible to dissociate these two conditions-increase of the nuclei and narrowing of the fibres, and they both indicate a marked nutritive change in the muscle. It is to be added that in some cylinders of the affected muscle there was a transparent, glassy condition, which has been variously designated as hyaline and colloid degeneration, and which is met with in the muscles in typhoid fever, \&c. This was not present in the narrowed fibres, and is probably of little importance in connexion with the pathology of this disease.

\section{attedical Sortictirs.}

\section{ROYAL MEDICAL \& CHIRURGICAL SOCIETY.}

Two Hundred Additional Cases, completing One Thousand Cases of Ovariotomy.-Development of a Layer of Elastic Fibres in Duct Cancer of the Breast.-Trephining in Epilepsy.

THE ordinary meeting of this Society was held on the 22nd inst., J. E. Erichsen, Esq., F.R.S., President, in the chair. The chief contribution was a paper by Mr. Spencer Wells, summarising the results of two hundred cases of ovariotomy, completing one thousand cases under his care. The President complimented Mr. Wells in glowing terms, and observed that the subject had been so recently and fully debated that there was little room for discus. sion.

The following is an abstract of the paper "On Two Hundred Additional Cases, completing One Thousand Cases of Orariotomy, with Remarks on Recent Improvements in the Operation," by Mr. T. SPENCER WELLS. The author presents in a table (similar in form to those in which he has brought before the Society all his cases of ovariotomy up to the eight hundredth), the particulars of 200 additional cases. The mortality of the ninth series was seventeen, of the tenth, eleven. Among the 1000 patients 231 have died and 769 recovered; but the mortality has steadily diminished from thirty-four in the first hundred to eleven in the last. Since the eight hundred and eighty-eighth case all the operations have been in private practice, and all have been done antiseptically, the result being a mortality of 10.6 . The author inquires how far this lessened mortality is due to antiseptic precautions or to other recent improvements in the mode of operating, describ. ing in detail various modifications in each step of the operation. - The PRESIDEnTsaid he would be expressing the feelings not only of the Society, but of the profession and public gene. rally by conveying their very best thanks to the illustrious author of this great work. For no man had done such a work in surgery as to have recorded 1000 cases of any one great operation with so small a mortality. Nothing can redound more to the credit, not only of Mir. Wells, but of surgery that such great results had been achieved by him. "I have lived," continued Mr. Erichsen, "through the whole period covered by the operation, and have been present at meetings of this Society when the introduction of the operation was being discussed; and I cannot but call to mind the obloquy (in which I never myself shared, for I performed the operation myself until I left it in better hands) which attended the operation and the operator. It is something to have lived through an epoch of surgery which has seen an operation of this magnitude not only survive that obloquy, but become one of the most successful operations in surgery, when performed with sufficient care, attention to detail, and, of course, personal skill. Surgeons may go further, and say this, that surgery is more indebted to obstetricians (I do not use that word - which I abominate-gynæcologists) for great improvements effected in operative surgery, for it is to them we owe the great precantions which, independently of antiseptic or Listerian method, tended to lower the mortality of ordinary surgical cases. One cannot but feel that the thanks to the author of the successful completion of 1000 eases should extend far beyond the limits of this room and this Society; they are due to him from the profession and suffering humanity at large."-Mr. WILLETT asked the author if he had in any way modified the aftertreatment of his cases, especially as regards the practice of free sweating; for he hinself had found in nearly every case a rise of temperature to $102^{\circ}$ or even $104^{\circ}$ about twelve hours after the operation. This rise was quite ephemeral, the temperature falling below $100^{\circ}$ within the next twelve hours; nor did it appear to act injuriously. He had associated this symptom with the practice of placing the patient in a heated room and covering ber with hot blankets, with the intention to promote free action of the skin. Ont of twenty cases Mr. Willett had had a mortality of three.-Mr. SPENCEP WELLS, in reply, said that for several years past he had discarded the practice of extreme overheating. In former days this was carried to a great extent, even to filling the room with steam. He believed. Mr. Willett's explanation of the rise of temperature in his cases to be correct; and it was certainly curious that whereas now, in a whole year, he (Mr. Wells) had not had one case with a temperature above $101^{\circ}$, he used frequently to have cases with the temperature reach. ing $104^{\circ}$, or even $106^{\circ}$ and $168^{\circ}$. He thanked the President for his kindly remarks, and said that such an appro. bation from the Chair was quite sufficienc reward for his work.

Dr. George ThIn read a paper "On the Development of a Layer of Elastic Fibres in Duct Cancer of the Breast." The paper gives a summary of the results of an examination into the nature of a layer of elastic substance described by the author in a paper read before the Society last session as surrounding epithelial masses in duct cancer. The layer is analogous to the elastic layer described by Henle as surrounding the lactiferous ducts, is composed of interlacing minute elastic fibres, contains no white fibrous tissue, although a few capillary bloodvessels and leucocytes are found in it, and is separated from the cell-mass by a mem. brana propria. Its significance is to be found in its association with a new enithelium which takes its origin in duct epithelium, and in the illustration it affords of the retention by a cancerous epithelium of one of the distinctive attributes of the special epithelium from which the morbid growth sprung; and, further, in the unexplained connexion between the development of epithelium and of elastic fibres. A nucleated membrana propria is described as being present 